\title{
Associations between selected training stress measures and fitness changes in male soccer players
}

\begin{abstract}
Purpose: The purpose of this study was to investigate the relationship of accumulated Global Positioning System (GPS)accelerometer-based and heart rate (HR)-based training metrics to changes in high-intensity intermittent running capacity during an inseason phase in professional soccer players. Method: Eleven male professional players (mean $\pm \mathrm{SD}$, age: $27.2 \pm 4.5$ years) performed the 30-15 Intermittent Fitness Test (30-15 IFT) before and after a fiveweek in-season training phase, and the final velocity ( $\mathrm{V}_{\mathrm{IFT}}$ ) was considered as players' high-intensity intermittent running capacity. During all sessions, Edwards' training impulse (Edwards' TRIMP), Banister's TRIMP, Z5 TRIMP, training duration, total distance covered, New Body Load (NBL), high-intensity running performance (distance covered above $14.4 \mathrm{~km} \cdot \mathrm{h}^{-1}$ ), and very highintensity running performance (distance covered above $19.8 \mathrm{~km} \cdot \mathrm{h}^{-}$ $\left.{ }^{1}\right)$ were recorded. Results: The players' VIFT showed a most likely moderate improvement $(+4.3 \%, 90 \%$ confidence limits $[3.1 ; 5.5 \%]$, effect size ES, 0.70 [0.51; 0.89]). Accumulated NBL, Banister's TRIMP and Edwards' TRIMP showed large associations ( $r=0.51$ to 0.54 ) with changes in $V_{\text {IFT }}$. Very large relationship was also observed between accumulated Z5 TRIMP $(r=0.72)$ with changes

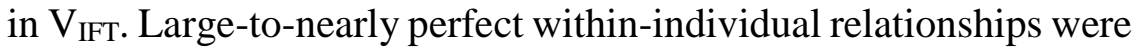
observed between NBL and some of the other training metrics (i.e., Edwards' TRIMP, Banister's TRIMP, training duration, and total distance) in 10 out of 11 players. Conclusions: HR-based training metrics can be used to monitor high-intensity intermittent running capacity changes in professional soccer players. The dose-response relationship is also largely detected using accelerometer-based metrics (i.e., NBL) to track changes in high-intensity intermittent running capacity of professional soccer players.
\end{abstract}

Key Words; Fitness, high-intensity running, New Body Load, Edwards' TRIMP, monitoring 
Soccer is an intermittent team sport comprising highintensity actions interspersed with short recovery periods ${ }^{1}$. During match play, players are required to cover $\sim 10-12 \mathrm{~km}$ at a high intensity (i.e., $80-90 \%$ of maximal HR $\left.\left[\mathrm{HR}_{\max }\right]\right)^{1}$. Success in match physical performance is therefore influenced by well-developed high-intensity running capacity ${ }^{2}$, which can be trained using generic or specific high-intensity interval training ${ }^{3}$.

During the in-season phase, professional soccer players are mostly involved in high volume skill-based training, aiming to improve technical, tactical and fitness abilities simultaneously ${ }^{4}$. The reported high variability within the skill-based training regime causes players to experience various external and internal training loads. Indeed, even with similar external training loads, athletes might respond differently to the stimuli based on their individual characteristics (e.g., age, physical qualities, position, and nutritional status ${ }^{5}$.

Individual monitoring of various external and internal training load variables is a strategy that is commonly used in highlevel team sport athletes to reduce the risk of injuries and/or improve performance ${ }^{6,7}$. External load is usually monitored by GPS technology $y^{8}$, while internal load can be quantified objectively using heart rate $(\mathrm{HR})^{6}$ and subjectively using the session rating of perceived exertion (sRPE) ${ }^{9}$.

For a measure of training load to be valid it is important to establish its association with any adaptations in physical qualities due to training, i.e. the dose-response relationship ${ }^{10-12}$. Investigations on the dose-response relationship between HR-based methods and changes in physical qualities have been equivocal. Some authors have proposed promising relationships between HRbased training loads and changes in aerobic fitness ${ }^{10,13-16}$. Conversely, Campos-Vazquez et al. ${ }^{17}$ reported no relationship between HR-derived measures of exercise load and changes in highintensity intermittent fitness but showed large-to-very large doseresponse associations when using training duration $(\mathrm{r}=0.72)$ or sRPE $(r=0.70)$, reinforcing that adding RPE did not improve the dose-response relationship. These differences between studies might be due to different criteria used as the fitness outcome (i.e., lactate threshold, maximal oxygen uptake, and high-intensity intermittent running capacity) that highlights the need to further elucidate the association between training load and the adaptive response to training.

The emergence of accelerometer-based training load measures has seen these metrics used increasingly in soccer alongside other measures of internal and external load ${ }^{6}$. These measures are 
reliable $^{18}$, yet their validity remains an area for debate ${ }^{18,19}$. Moreover, while strong relationships have been observed between accelerometer-based and HR-based training loads in some studies ${ }^{20 \text {, }}$ ${ }^{21}$, the dose-response relationship with changes in aerobic fitness have been questioned ${ }^{12}$. Previous studies have usually analyzed the relationships between internal and external load measures using a between-individual approach ${ }^{19-21}$, whereas examining withinindividual correlations might provide greater insights. It might therefore be of interest to examine within-individual relationships between measures derived from accelerometers combined with other internal and external training load measures.

Although training variables such as distance covered above $14.4 \mathrm{~km} \cdot \mathrm{h}^{-1}$ and time spent above $90 \%$ of maximum HR $\left(\min >90 \% \mathrm{HR}_{\max }\right)$ are currently recommended for monitoring training outcomes in professional soccer players ${ }^{11}$, the emergence of novel accelerometer-based training load metrics might offer further insight into the dose-response relationship. To date only a few studies ${ }^{10,12,16}$ have evaluated the utility of several training load measures to understand the dose-response relationship in amateur or professional youth team sport players. However, the standard of participants and training studied by these investigations ${ }^{10,12,16}$ prevents any meaningful comparison to understand the relationships between different training load measures and fitness outcome in professional adult athletes. Therefore, the purpose of this study was to investigate the relationship between accelerometer-based and HR-based training metrics and seasonal short-term (i.e., over a fiveweek period) changes in high-intensity intermittent running performance in professional soccer players.

\section{Methods}

\section{Subjects}

A variety of training metrics, including both measures of internal and external load, were recorded during a five-week inseason period in 11 professional soccer players (mean \pm SD, age: $27.2 \pm 4.5$ years; height: $180.4 \pm 9.0 \mathrm{~cm}$; body mass: $72.7 \pm 6.6 \mathrm{~kg}$ ). All players were selected from a single professional soccer team competing in the Persian Gulf Cup. The study was approved by the institution's ethics review committee and conformed to the Declaration of Helsinki. All players were informed of the risks and benefits of participating in the study and provided written informed consent beforehand.

\section{Design}

Data were collected during the mid-season phase, after 15 official matches. During the five-week period, players participated 
in 21 training sessions (consisting technical, tactical and conditioning [comprising resistance training, high-intensity interval training, speed, agility and power] drills) and four official matches (Figure 1). Players with having less than 10 training sessions were excluded from analyses. Mean \pm SD of the number of training sessions completed by players was $14.9 \pm 3.4$. Players completed a high-intensity intermittent fitness test before and after the selected in-season phase.

\section{Methodology}

\section{0-15 Intermittent Fitness Test}

After habituation, each player's high-intensity intermittent running capacity was assessed using the 30-15 Intermittent Fitness Test (30-15 $\left.5_{\mathrm{IFT}}\right)^{22}$ on natural turf, at the same time (11-12 am) and in similar environmental conditions (temperature at $16-18{ }^{\circ} \mathrm{C}$, relative humidity 10-15\%). Although training loads during the week before pre- and post-30-15 IFT were not identical, wellness and heart rate variability measures were monitored to assure maximal tests were not impaired by residual fatigue. The test has been shown to be valid and sensitive in soccer players ${ }^{3}$. Before the test, players completed a standardized warm-up comprising 15 min of low-intensity running and dynamic stretching. Thereafter, players completed the test that consisted of $30 \mathrm{~s}$ shuttle runs interspersed with $15 \mathrm{~s}$ passive recovery periods. The test started at $8 \mathrm{~km} / \mathrm{h}$ and increased by $0.5 \mathrm{~km} / \mathrm{h}$ for each successive $30 \mathrm{~s}$. The test ended when a player reached exhaustion or could not reach the next $3 \mathrm{~m}$ zone on the audio signal on three consecutive occasions. The speed at termination of the 3015 IFT $_{\left(\mathrm{V}_{\mathrm{IFT}}\right)}$ was recorded for analysis. Maximal HR was also recorded using a HR monitor (1-s sample recording, Polar T34, Polar Electro Oy, Kempele, Finland) and taken as the highest value attained in the test.

\section{Training metrics}

Only training metrics, including both external and internal loads, during training sessions were recorded because players did not wear GPS devices during five official matches that were played during the selected period. During all training sessions, movement characteristics and HR were collected using a $15 \mathrm{~Hz}$ (interpolated from $5 \mathrm{~Hz}$ sampling) microtechnology device (SPI Pro X, GPSports, Canberra, Australia) synchronized with a HR monitor recorded at 1second intervals (Polar T34, Polar Electro Oy, Kempele, Finland). Synchronization between SPI units and HR chest straps for all individual players were checked before commencing the training sessions by one of coaching staff. Training duration, total distance covered, high-intensity running performance (HIR; distance covered above $14.4 \mathrm{~km} \cdot \mathrm{h}^{-1}$ ), and very high-intensity running 
performance (VHIR; distance covered above $19.8 \mathrm{~km} \cdot \mathrm{h}^{-1}$ ) were recorded. New Body Load (NBL) was also recorded by integrating all forces measured by a $100 \mathrm{~Hz}$ tri-axial accelerometer embedded within the microtechnology device ${ }^{23}$. All data were analysed using the Team AMS software (GPSports, Version 2.1). Edwards' training impulse (Edwards' TRIMP) ${ }^{24}$, Banister's training impulse (Banister's TRIMP) ${ }^{25}$, and time spent above $90 \%$ of $\mathrm{HR}_{\max }$ (i.e., Z5 TRIMP) were used as measures of internal training loads or intensity. The formulas used for calculating Banister's TRIMP and Edwards' TRIMP are shown in Table 1. The maximal HR recorded during pre-test (i.e. during 30-15 $5_{\mathrm{IFT}}$ ) was used for calculating Edwards' TRIMP, and Z5 TRIMP for each individual player.

**Table 1 about here please **

\section{Statistical Analyses}

The results are presented as mean $\pm \mathrm{SD}$ and/or $90 \%$ confidence intervals (CI) where specified. Within-group changes in $\mathrm{V}_{\text {IFT }}$ were expressed as percentage changes and as standardized differences or standardized effect size (ES, 90\% confidence limit [90\% CL]). Effect sizes were interpreted as: < 0.2: trivial; 0.2-0.6: small; 0.6-1.2: moderate; $>1.2$ : large ${ }^{26}$. Probabilities were calculated based on smallest worthwhile change (SWC, determined by $0.2 \times$ between-subjects $\mathrm{SD})^{27}$. If the probabilities of the effect being substantially positive and negative were both $>5 \%$, the effect was reported as unclear; the effect was otherwise clear and reported as the magnitude of the observed value. The scale was as follows: $25-$ 75\%, possible; 75-95\%, likely; 95-99\%, very likely; >99\%, almost certain $^{27}$. Individual $\mathrm{V}_{\text {IFT }}$ changes were also assessed using a specifically designed spreadsheet ${ }^{28}$ in which both the typical error of the measurement of the test and the SWC were considered ${ }^{22}$. For individual analyses, only changes rated as at least likely (>75\%) were considered as substantial ${ }^{28}$. Pearson's correlation coefficients were used to assess the relationship between accumulated external and internal training loads and changes in $\mathrm{V}_{\mathrm{IFT}}$ (i.e., dose-response associations). Within-individual relationships between NBL and other training metrics were also assessed with Pearson's correlation coefficients. The correlation coefficient $(\mathrm{r}, 90 \% \mathrm{CL})$ was ranked as trivial $(<0.10)$, small $(>0.10$-to-0.30), moderate $(>0.30$-to- 0.50$)$, large (>0.50-to-0.70), very large ( $>0.70$-to- 0.90$)$, nearly perfect (>0.90-to-0.99), and perfect (1) ${ }^{27}$. If the $90 \%$ CI overlapped small positive and negative values, the magnitude was deemed unclear.

\section{Results}


The mean $\pm \mathrm{SD}$ values of relative accumulated NBL, Edwards' TRIMP, and Banister's TRIMP were 126.3 $\pm 30.1,166.8$ \pm 23.2 , and $96.0 \pm 11.0$ AU (arbitrary units, AU), respectively. Relative accumulated Z5 TRIMP was $4.3 \pm 3.3 \mathrm{~min}$. Relative accumulated HIR and VHIR distances were 778.0 \pm 152.8 and 253.7 $\pm 92.2 \mathrm{~m}$, respectively. Relative accumulated total distance covered and training duration were $5031.0 \pm 408.4 \mathrm{~m}$, and $64.6 \pm 4.8 \mathrm{~min}$, respectively. The NBL and Edwards' TRIMP distribution during various training sessions is shown in Figure 1 . The $\mathrm{V}_{\text {IFT }}$ showed a most likely moderate improvement $(+4.3 \%, 90 \%$ confidence limits CL [3.1; 5.5\%], effect size ES, 0.70 [0.51; 0.89]) from $19.0 \pm 1.0$ to $19.8 \pm 1.0 \mathrm{~km} \cdot \mathrm{h}^{-1}$. Individual analyses showed that $45 \%(\mathrm{n}=5 / 11)$ of players substantially improved their high-intensity intermittent running performance (Figure 2).

\section{**Figures 1-2 about here please **}

Large associations were observed between accumulated NBL, Banister's TRIMP and Edwards' TRIMP with changes in $\mathrm{V}_{\text {IFT }}$ (Figure 3). A very large relationship was also observed between accumulated Z5 TRIMP with changes in VIFT (Figure 3). VHIR showed unclear association with changes in $\mathrm{V}_{\text {IFT }}(r=0.06, \mathrm{CL}$ [0.48 ; 0.57]). Unclear correlations were observed between HIR ( $r=$ 0.23 , CL $[-0.33 ; 0.67])$ and training duration ( $r=0.26$, CL [-0.30; $0.69])$ with changes in VIFT. An unclear correlation ( $r=0.33$, CL [$0.23 ; 0.73])$ was also observed between total distance covered and changes in $\mathrm{V}_{\text {IFT. }}$.

\section{**Figures 3 about here please ** \\ Large-to-nearly perfect within-individual relationships (range $r=0.55$ to 0.92 ) were observed between NBL and some training metrics (i.e., Edwards' TRIMP, Banister's TRIMP, training duration, and total distance) in 10 out of 11 players (Table 2).}

**Tables 2 about here please **

\section{Discussion}

Determining the potential for different internal or external training load variables to track fitness changes in competitive soccer players is an important outcome of the monitoring process ${ }^{6,11,20}$. Moreover, modifying training loads based on the most sensitive monitoring variables assures the maintenance - or even the improvement - of soccer players' physical qualities during the competitive season. The main finding of this study was the potential usefulness of HR-based training metrics (i.e., Banister's TRIMP, Edwards' TRIMP, and Z5 TRIMP) and NBL for monitoring 
changes in high-intensity intermittent running performance in professional soccer players.

The moderate improvement in $\mathrm{V}_{\text {IFT }}$ observed in our study ( 4\%, ES: 0.70) is in agreement with previous investigations reporting positive changes in soccer players' fitness after short training interventions $\mathrm{s}^{3,13-15,17}$. It is worth noting, however, that most previous investigations were conducted during pre-season preparations when training loads are generally higher ${ }^{4}$ and when the main goal of training is to improve players' physical qualities. The smaller improvement in high-intensity intermittent running capacity observed in the present study compared to the change magnitude (ES: 1.15) reported by Campos-Vazquez et al. ${ }^{17}$ might, therefore, be explained by the different competition phase (i.e. in-season cf. preseason) and the reduced emphasis on conditioning content within the training. This is further supported by the very low training loads observed in our players during the 5-week period and highlights a potential reluctance by coaches to incorporate physically demanding training during the soccer in-season period.

Large-to-very large within-individual correlations observed here between NBL and selected internal load metrics (i.e., Edwards' TRIMP, Banister' TRIMP) in 90\% of players supports the work of Casamichana et al. $^{21}$ in which associations were observed between accelerometer and other internal load measures (Edwards' TRIMP and sRPE). Such associations are expected given that increases in accelerations and decelerations incur a greater physiological $\operatorname{load}^{29}$. The moderate-to-nearly perfect withinindividual relationships observed between NBL and total distance covered as well as training duration also suggest that computing NBL be associated to these simple training metrics.

Large-to-very large positive relationships between HRbased training metrics (i.e., Banister's TRIMP, Edwards' TRIMP and Z5 TRIMP) and fitness outcome are consistent with similar relationships reported elsewhere ${ }^{10,13,15,16}$. Our results also support, at least in part, the findings of Taylor et el. ${ }^{12}$ that showed a curvilinear dose-response relationship between Banister's TRIMP and individualized TRIMP with changes in maximal aerobic fitness. Our findings are, however, in contrast to those of Campos-Vazquez et al. ${ }^{17}$ who reported no relationship between HR-derived measures of exercise load and changes in $\mathrm{V}_{\text {IFT }}$. It is worth mentioning that basal $\mathrm{V}_{\text {IFT }}$ level of players in the present study was different from the study of Campos-Vazquez et al. ${ }^{17}\left(\mathrm{~V}_{\mathrm{IFT}} ; 19.0\right.$ versus $\left.20.1 \mathrm{~km} \cdot \mathrm{h}^{-1}\right)$ and consequently it might have influenced the dose-response relationships. The relationship between HR-based training loads and fitness changes in the present study are almost similar or of a lower magnitude than have been previously reported using $\mathrm{SRPE}^{17}$ or HR- 
based measures ${ }^{12-16}$. We are also the first to report a large relationship between accumulated NBL and changes in highintensity intermittent running capacity. Unclear relationships between HIR and VHIR with changes in VIFT observed here is in agreement with the results of recent study by Fitzpatrick et al. ${ }^{16}$ in which unclear correlations were observed between arbitrary running thresholds and changes in aerobic fitness. Collectively, our results suggest using HR-based training loads or high-intensity HR thresholds as well as accelerometer-based load metrics (i.e., NBL) to better track high-intensity running or aerobic fitness changes in professional soccer players during in-season phases. Our study also showed that despite no physiological or metabolic basis for Edwards' TRIMP, its dose-response relationship was similar to Banister's TRIMP. However, a previous study ${ }^{10}$ suggests that a truly individualized training load metric (e.g. individualized TRIMP) shows a stronger dose-response relationship compared to arbitrary metrics.

Although large-to-very large dose-response relationships were observed for some training metrics, the high variability among the players are well represented in Figure 3. As an example, there are six players showing 3-4 \% improvement in $\mathrm{V}_{\text {IFT }}$ after the training period while they have been exposed to various accumulated training metrics for NBL (from 1000 to $2500 \mathrm{AU}$ ) (Figure 3/A), Z5 TRIMP (from $\sim 25$ to $50 \mathrm{~min}$ ) (Figure 3/B), Edwards' TRIMP (from $~ 800$ to $3000 \mathrm{AU}$ ) (Figure 3/C), and Banister' TRIMP (from $\sim 1000$ to $2700 \mathrm{AU}$ ) (Figure 3/D). These results confirm the finding of a recent study that reported large-to-very large dose-response relationships between accumulated SRPE and changes in submaximal HR measures, but also that meaningful variations existed among individuals ${ }^{7}$.

An improvement in players' fitness, as determined by the $\mathrm{V}_{\text {IFT, }}$, are in contrast to those of Akubat et al. ${ }^{10}$, who reported no changes in submaximal markers of exercise capacity (i.e. lactate threshold) after six weeks of training in youth soccer players. Similarly, the observed large dose-response relationships between NBL and changes in fitness contrasts those of Taylor et al. ${ }^{12}$ who reported only associations between fitness and HR-based loads. The large dose-response relationship observed here between NBL and changes in high-intensity intermittent running capacity supports the use of accelerometer-based GPS measures to track fitness changes. It seems that the criteria used to determine fitness outcome $\left(\mathrm{VO}_{2 \max }\right.$ and lactate thresholds cf. $\mathrm{V}_{\mathrm{IFT}}$ ) might also be important in establishing the dose-response relationship. The $\mathrm{V}_{\mathrm{IFT}}$, as a measure of high-intensity intermittent fitness, depends not only on the individual players' aerobic power but also on the players' abilities 
regarding acceleration, deceleration, change of direction, and recovery from intensified bursts of activity ${ }^{22}$. While very large positive dose-response relationships observed here between Z5 TRIMP and changes in $\mathrm{V}_{\text {IFT }}$ supports previous recommendations of using this measure as a strong stimulus for enhancing maximal oxygen uptake $\left(\mathrm{VO}_{2 \max }\right)^{13,14}$, high-intensity intermittent running capacity might also be dependent on both metabolic and neuromuscular-load measures ${ }^{30}$; supporting the use of other combined load metrics (e.g., NBL, Banister's TRIMP and Edwards' TRIMP). Our findings therefore support the sensitivity and specificity of $\mathrm{V}_{\mathrm{IFT}}$ to determining changes in soccer players' fitness after intensified soccer training ${ }^{3,17}$. However, this study is limited by examining only training loads in part of an in-season phase for a small sample of a single professional team. It should also be noted that the small sample size of this study has probably contributed to the relatively wide confidence intervals observed in dose-response correlations (e.g., 0.32-to-0.90 for Z5 TRIMP). These relationships should therefore be interpreted with some caution. The lower training load and focus more on technical and tactical components might have influenced the adaptations during this period. Future studies in a longer training phase with greater conditioning emphasis are encouraged.

\section{Practical Applications}

It is suggested that practitioners use NBL and HR-based training metrics (Z5 TRIMP, Edwards' TRIMP, and Banister's TRIMP) to track changes in high-intensity intermittent running capacity of soccer players. Practitioners might need to implement high-intensity exercises during in-season to elicit more time spent above $90 \%$ of $\mathrm{HR}_{\max }$ into their training plans to effectively improve players' highintensity intermittent fitness.

\section{Conclusions}

In conclusion, the present study showed large-to-very large dose-response relationships between NBL and HR-based training loads with changes in high-intensity intermittent running capacity of professional soccer players during an in-season phase. About $90 \%$ of players showed large-to-nearly perfect within-individual correlations between NBL and some external training load metrics (i.e., training duration, total distance covered) which did not have any strong dose-response associations to changes in high-intensity intermittent running capacity, reinforcing the limitation of between variable correlations (i.e., dose-dose relationship) for monitoring changes in soccer players' fitness status. Trivial-to-moderate unclear dose-response relationships between training duration, total distance, HIR and VHIR metrics with changes in VIFT also 
highlights the limitation of using some arbitrary external training metrics to track fitness changes in professional soccer players. The findings of the present study also provide evidence that players can experience moderate improvements in high-intensity intermittent fitness during the in-season phase, assuming the training content is appropriate.

\section{Acknowledgements}

The authors of this study have no conflict of interest with the issues addressed in study. No funding was received for the accomplishment of this field study.

\section{References}

1. Stolen T, Chamari K, Castagna C, Wisloff U. Physiology of soccer: An update. Sports Med. 2005;35:501-537.

2. Castagna C1, Impellizzeri F, Cecchini E, Rampinini E, Alvarez JC. Effects of intermittent-endurance fitness on match performance in young male soccer players. J Strength Cond Res. 2009;23:1954-1959.

3. Buchheit M, Rabbani A. The 30-15 intermittent fitness test versus the yo-yo intermittent recovery test level 1: Relationship and sensitivity to training. Int J Sports Physiol Perform. 2014;9:522524.

4. Jeong T-S, Reilly T, Morton J, Bae S-W, Drust B. Quantification of the physiological loading of one week of "preseason" and one week of "in-season" training in professional soccer players. J Sports Sci. 2011;29:1161-1166.

5. Impellizzeri FM, Rampinini E, Marcora SM. Physiological assessment of aerobic training in soccer. J Sports Sci. 2005;23:583592.

6. Akenhead R, Nassis GP. Training load and player monitoring in high-level football: current practice and perceptions. Int J Sports Physiol Perform. 2016;11:587-593.

7. Rabbani A, Kargarfard M, Twist C. Fitness monitoring in elite soccer players: Group vs. individual analyses. J Strength Cond Res. 2018; In Press.

8. Cummins C, Orr R, O’Connor H, West C. Global positioning systems (GPS) and microtechnology sensors in team sports: A systematic review. Sports Med. 2013;43:1025-42.

9. Impellizzeri FM, Rampinini E, Coutts AJ, Sassi A, Marcora SM. Use of RPE-based training load in soccer. Med Sci Sports Exerc. 2004;36:1042-1047. 
10. Akubat I, Patel E, Barrett S, Abt G. Methods of monitoring the training and match load and their relationship to changes in fitness in professional youth soccer players. J Sports Sci. 2012;30:1473-1480.

11. Jaspers A, Brink MS, Probst SG, Frencken WG, Helsen WF. Relationships between training load indicators and training outcomes in professional soccer. Sports Med. 2016:1-12.

12. Taylor R, Sanders D, Myers T, Abt G, Taylor CA, Akubat I. The dose-response relationship between training load and aerobic fitness in academy rugby union players. Int J Sports Physiol Perform. 2018;13:163-169.

13. Castagna C, Impellizzeri FM, Chaouachi A, Bordon C, Manzi V. Effect of training intensity distribution on aerobic fitness variables in elite soccer players: A case study. J Strength Cond Res. 2011;25:66-71.

14. Castagna C, Impellizzeri FM, Chaouachi A, Manzi V. Preseason variations in aerobic fitness and performance in elitestandard soccer players: A team study. J Strength Cond Res. 2013;27:2959-65.

15. Manzi V, Bovenzi A, Impellizzeri MF, Carminati I, Castagna C. Individual training-load and aerobic-fitness variables in premiership soccer players during the precompetitive season. $J$ Strength Cond Res. 2013;27:631-636.

16. Fitzpatrick JF, Hicks KM, Hayes PR. Dose-response relationship between training load and changes in aerobic fitness in professional youth soccer players. Int J Sports Physiol Perform. 2018;10:1-22.

17. Campos-Vazquez MA, Toscano-Bendala FJ, Mora-Ferrera JC, Suarez-Arrones LJ. Relationship between internal load indicators and changes on intermittent performance after the preseason in professional soccer players. J Strength Cond Res. 2017;31:1477-1485.

18. Barreira P, Robinson MA, Drust B, Nedergaard N, Raja Azidin RMF, Vanrenterghem J. Mechanical Player Load ${ }^{\mathrm{TM}}$ using trunk-mounted accelerometry in football: Is it a reliable, task-and player-specific observation? J Sports Sci. 2017;35:1674-1681.

19. Gomez-Piriz PT, Jiménez-Reyes P, Ruiz-Ruiz C. Relation between total body load and session rating of perceived exertion in professional soccer players. J Strength Cond Res. 2011;25:21002103.

20. Scott BR, Lockie RG, Knight TJ, Clark AC, de Jonge XAKJ. A Comparison of methods to quantify the in-Season training load of professional soccer players. Int J Sports Physiol Perform. 2013;8:195-202. 
21. Casamichana D, Castellano J, Calleja-Gonzalez J, San Román J, Castagna C. Relationship between indicators of training load in soccer players. J Strength Cond Res. 2013;27:369-74.

22. Buchheit M. The 30-15 intermittent fitness test: accuracy for individualizing interval training of young intermittent sport players. J Strength Cond Res. 2008;22:365-74.

23. Ehrmann FE, Duncan CS, Sindhusake D, Franzsen WN, Greene DA. GPS and injury prevention in professional soccer. $J$ Strength Cond Res. 2016;30:360-7.

24. Edwards S. The heart rate monitor book. 1994;26:647.

25. Morton RH, Fitz-Clarke JR, Banister EW. Modeling human performance in running. J Appl Physiol. 1985;69:1171-7.

26. Batterham AM, Hopkins WG. Making meaningful inferences about magnitudes. Int $J$ Sports Physiol Perform. 2006;1:50-57.

27. Hopkins W, Marshall S, Batterham A, Hanin J. Progressive statistics for studies in sports medicine and exercise science. Med Sci Sports Exerc. 2009;41:3-13.

28. Hopkins W. Precision of the estimate of a subject's true value (Excel spreadsheet). A New View of Statistics sportsci org: Internet Society for Sport Science. 2000.

29. Akenhead R, French D, Thompson KG, Hayes PR. The Physiological Consequences of acceleration during shuttle running. Int J Sports Med. 2014;36:302-307.

30. Buchheit M, Laursen PB. High-intensity interval training, solutions to the programming puzzle. Part II: anaerobic energy, neuromuscular load and practical applications. Sports Med. 2013;43:927-954. 


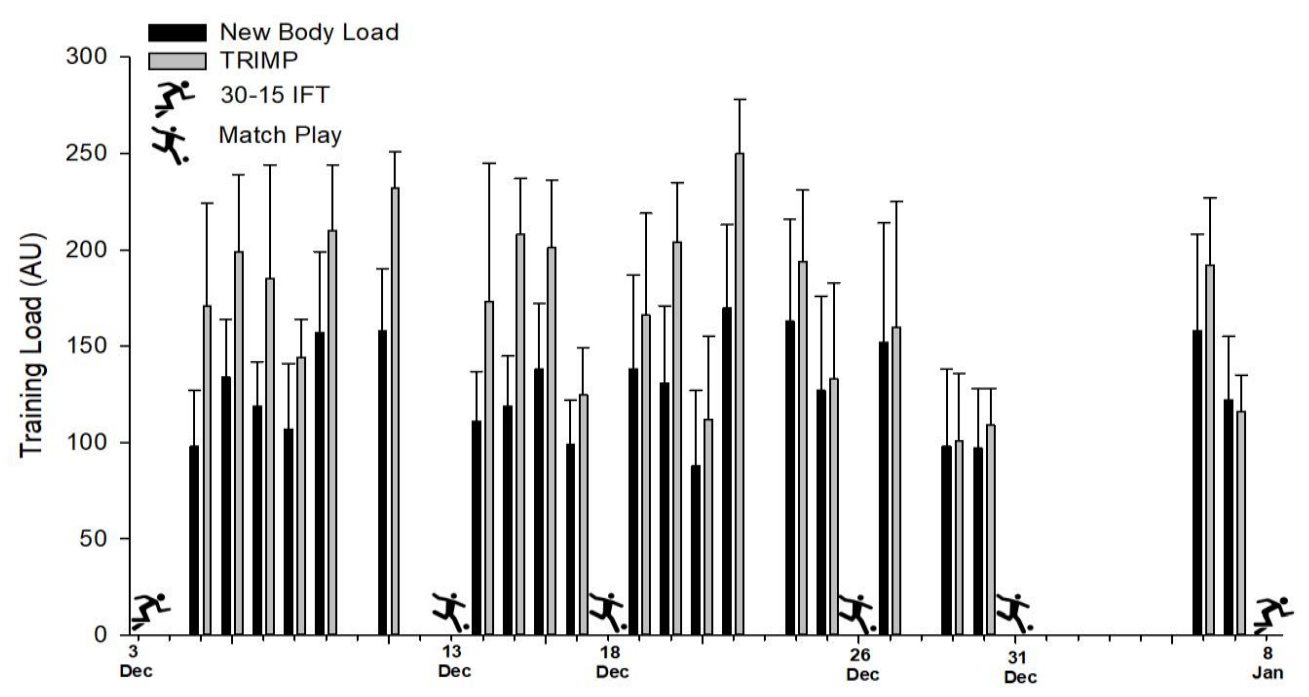

Figure 1. New Body Load and Edwards' TRIMP distribution during selected in-season phase. 30-15 IFT: 30-15 Intermittent Fitness Test; AU: arbitrary unit; Error bars represent the standard deviation.

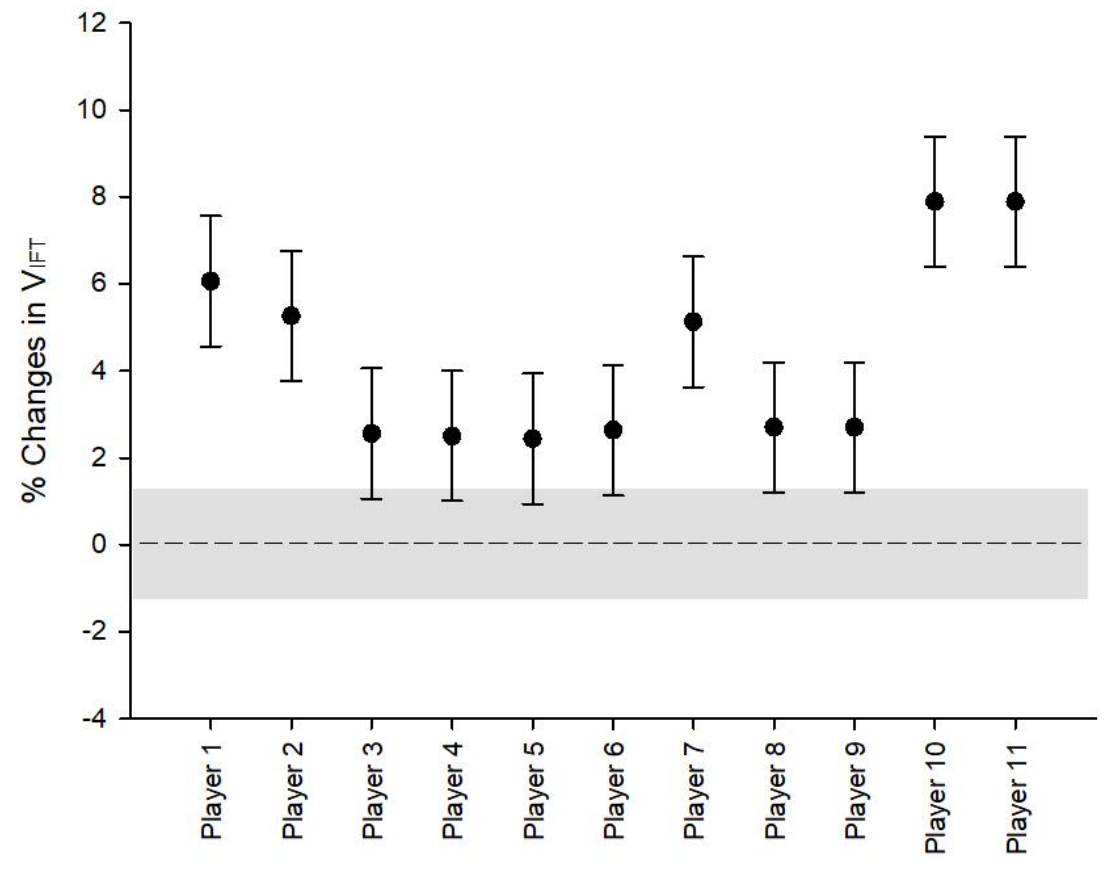


Figure 2. Individual changes in $\mathrm{V}_{\mathrm{IFT}}$. Shaded area represents the smallest worthwhile change (SWC). Error bars represent the typical error of measurements. $\mathrm{V}_{\text {IFT: }}$ Maximal velocity reached during the last stage of 30-15 Intermittent Fitness Test.
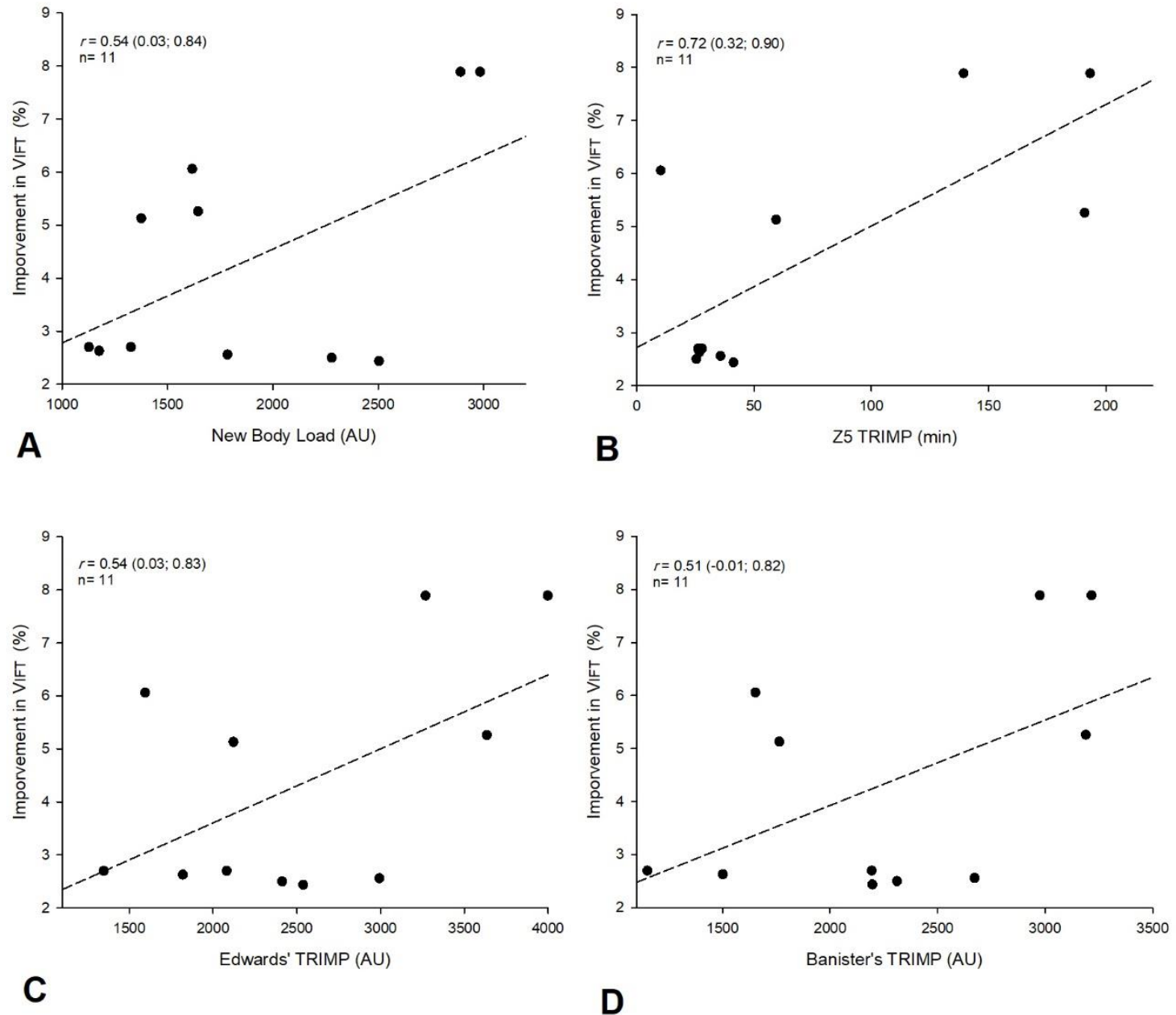
Table 1. Formulas for Edwards' TRIMP and Banister's TRIMP

TRIMP method Formula

Edwards' TRIMP

TRIMP $=($ duration in zone $1 \times 1)+($ duration in zone $2 \times 2)+($ duration

in zone $3 \times 3)+($ duration in zone $4 \times 4)+($ duration in zone $5 \times 5)$

zone $1=50$-to- $60 \%$ of $\mathrm{HR}_{\max }$, zone $2=60$-to- $70 \%$ of $\mathrm{HR}_{\max }$, zone $3=$

70-to- $80 \%$ of $\mathrm{HR}_{\max }$, zone $4=80$-to-90\% of $\mathrm{HR}_{\max }$, and zone $5=90$ -

to- $100 \%$ of $\mathrm{HR}_{\max }$

Banister's TRIMP $\quad$ Banister's TRIMP $=\mathrm{D} \times(\Delta$ heart rate ratio $) \times \mathrm{e}^{(\mathrm{b} \times \Delta \text { heart rate ratio })}$

$\mathrm{D}=$ session duration, the constant $\mathrm{e}=2.718$, and weighting factor $\mathrm{b}=$ 1.92 for men

$\Delta$ heart rate ratio $=\left(\mathrm{HR}_{\mathrm{avg}}-\mathrm{HR}_{\mathrm{rest}}\right) \div\left(\mathrm{HR}_{\max }\right.$ during exercise $\left.-\mathrm{HR}_{\text {rest }}\right)$

HR: heart rate; TRIMP: training impulse; HRavg: average heart rate during exercise.

Figure 3. Relationships between accumulated training metrics and changes in the maximal velocity reached during the last stage 3015 Intermittent Fitness Test ( $\left.\mathrm{V}_{\text {IFT }}\right)$. TRIMP: training impulse; Z5 TRIMP; time spent more than $90 \%$ of maximal heart rate. 

Table 2. Within-individual relationships between New Body Load with other training load measures

\begin{tabular}{|c|c|c|c|c|c|c|c|}
\hline Subject & Edwards' TRIMP & Banister' TRIMP & Z5 TRIMP & HIR & VHIR & Time & Total Distance \\
\hline \multirow[t]{2}{*}{ Player 1} & $0.77(0.40 ; 0.92)$ & $0.73(0.33 ; 0.91)$ & $0.00(-0.50 ; 0.60)$ & $0.66(0.21 ; 0.88)$ & $0.53(0.01 ; 0.82)$ & $0.92(0.78 ; 0.98)$ & $0.62(0.14 ; 0.86)$ \\
\hline & Very large & Very large & Unclear & Large & Large & Nearly perfect & Large \\
\hline \multirow[t]{2}{*}{ Player 2} & $0.89(0.76 ; 0.95)$ & $0.61(0.28 ; 0.81)$ & $0.48(0.10 ; 0.74)$ & $-0.18(-0.54 ; 0.24)$ & $-0.14(-0.51 ; 0.27)$ & $0.81(0.61 ; 0.92)$ & $0.83(0.65 ; 0.92)$ \\
\hline & Very large & Large & Moderate & Unclear & Unclear & Very large & Very large \\
\hline \multirow[t]{2}{*}{ Player 3} & $0.86(0.71 ; 0.94)$ & $0.68(0.40 ; 0.85)$ & $0.41(0.02 ; 0.69)$ & $-0.02(-0.41 ; 0.37)$ & $0.09(-0.31 ; 0.46)$ & $0.78(0.56 ; 0.90)$ & $0.88(0.74 ; 0.94)$ \\
\hline & Very large & Large & Moderate & Unclear & Unclear & Very large & Very large \\
\hline \multirow[t]{2}{*}{ Player 4} & $0.81(0.60 ; 0.91)$ & $0.83(0.64 ; 0.92)$ & $0.04(-0.36 ; 0.44)$ & $-0.12(-0.50 ; 0.29)$ & $0.00(-0.40 ; 0.40)$ & $0.80(0.58 ; 0.91)$ & $0.82(0.62 ; 0.92)$ \\
\hline & Very large & Very large & Unclear & Unclear & Unclear & Very large & Very large \\
\hline \multirow[t]{2}{*}{ Player 5} & $0.82(0.57 ; 0.93)$ & $0.65(0.27 ; 0.85)$ & $0.39(-0.08 ; 0.72)$ & $0.24(-0.25 ; 0.63)$ & $0.33(-0.15 ; 0.69)$ & $0.76(0.46 ; 0.90)$ & $0.76(0.46 ; 0.90)$ \\
\hline & Very large & Large & Moderate & Unclear & Unclear & Very large & Very large \\
\hline \multirow[t]{2}{*}{ Player 6} & $0.79(0.46 ; 0.93)$ & $0.61(0.13 ; 0.86)$ & $0.80(0.47 ; 0.93)$ & $0.77(0.42 ; 0.92)$ & $0.71(0.30 ; 0.90)$ & $0.61(0.12 ; 0.86)$ & $0.61(0.12 ; 0.86)$ \\
\hline & Very large & Large & Very Large & Very large & Very large & Large & Large \\
\hline \multirow[t]{2}{*}{ Player 7} & $0.80(0.52 ; 0.92)$ & $0.56(0.12 ; 0.82)$ & $0.44(-0.05 ; 0.76)$ & $-0.14(-0.58 ; 0.36)$ & $0.02(-0.47 ; 0.49)$ & $0.87(0.66 ; 0.95)$ & $0.76(0.43 ; 0.91)$ \\
\hline & Very large & Large & Moderate & Unclear & Unclear & Very large & Very large \\
\hline \multirow[t]{2}{*}{ Player 8} & $0.70(0.23 ; 0.90)$ & $0.65(0.15 ; 0.88)$ & $0.48(-0.10 ; 0.81)$ & $-0.62(-0.87 ;-0.10)$ & $-0.49(0.82 ; 0.08)$ & $0.73(0.30 ; 0.91)$ & $0.90(0.69 ; 0.97)$ \\
\hline & Large & Large & Moderate & Large & Moderate & Very large & Very large \\
\hline Player 9 & $0.73(0.39 ; 0.90)$ & $0.81(0.54 ; 0.93)$ & $0.21(-0.30 ; 0.62)$ & $0.51(0.05 ; 0.80)$ & $0.45(-0.03 ; 0.77)$ & $0.74(0.41 ; 0.90)$ & $0.83(0.58 ; 0.94)$ \\
\hline
\end{tabular}




$\begin{array}{llllllll} & \text { Very large } & \text { Very large } & \text { Unclear } & \text { Large } & \text { Moderate } & \text { Verylarge } & \text { Very large } \\ \text { Player } 10 & 0.26(-0.17 ; 0.61) & 0.55(0.18 ; 0.78) & -0.17(-0.54 ; 0.26) & 0.18(-0.26 ; 0.55) & 0.20(-0.23 ; 0.57) & 0.44(0.03 ; 0.72) & 0.92(0.82 ; 0.97) \\ & \text { Unclear } & \text { Large } & \text { Unclear } & \text { Unclear } & \text { Unclear } & \text { Moderate } & \text { Nearly perfect } \\ \text { Player } 11 & 0.63(0.33 ; 0.82) & 0.61(0.30 ; 0.80) & 0.36(-0.02 ; 0.65) & -0.23(-0.56 ; 0.16) & -0.22(-0.55 ; 0.17) & 0.67(0.40 ; 0.84) & 0.89(0.78 ; 0.95) \\ & \text { Large } & \text { Large } & \text { Moderate } & \text { Unclear } & \text { Unclear } & \text { Large } & \text { Very large }\end{array}$

Pearson correlation coefficients are presented with $90 \%$ of confidence limits and their magnitudes. TRIMP: training impulse; Z5 TRIMP: time spent more than $90 \%$ of maximal heart rate; HIR: High-intensity running; VHIR: Very high-intensity running; VIFT: Maximal velocity reached during the last stage of 30-15 Intermittent Fitness Test. The correlation coefficient (r, 90\%CL) was ranked as trivial (<0.10), small ( $>0.10$-to$0.30)$, moderate $(>0.30$-to-0.50), large (>0.50-to-0.70), very large ( $>0.70$-to-0.90), nearly perfect $(>0.90$-to-0.99), and perfect $(1)$. 